\title{
Physical Fitness and Metabolic Profile among Malay Undergraduates of a Public University in Selangor Malaysia
}

\author{
M. EMAD ${ }^{1}$, M. KANDIAH ${ }^{2}$, W. K. LIM ${ }^{3}$, M. Y. BARAKATUN-NISAK ${ }^{1}$ \\ A. RAHMAT ${ }^{4}$, S. NORASRUDDIN ${ }^{4}$ AND M. APPUKUTTY ${ }^{4 *}$
}

\begin{abstract}
This study investigated health-related components of physical fitness consisting of morphological fitness (body fat \% or BF \%; Body Mass Index or BMI; and waist circumference or WC), metabolic fitness (blood glucose, lipid profiles and haemoglobin) and aerobic capacity $\left(\mathrm{VO}_{2} \mathrm{max}\right)$. This crosssectional study involved 324 undergraduates recruited voluntarily by systematic random sampling from a public university in the city Shah Alam, Selangor Malaysia. The respondents' aerobic capacity was measured by field fitness tests and anthropometric measurements using standard protocols. The mean BMI of respondents was $22.51 \pm 4.18 \mathrm{~kg} / \mathrm{m}^{2}$, and majority of the respondents $(93 \%)$ are within normal range of WC. The prevalence of underweight was $13.5 \%$ and overweight/obese was $20.2 \%$. The blood glucose levels of respondents were within the normal range (94.4\%) and about $5 \%$ of female respondents had moderate anaemia. More than $70 \%$ of the males and $25 \%$ of the females had poor $\mathrm{VO}_{2}$ max levels (aerobic capacity). In summary, the present results suggest the necessity of health promotion programme focusing on physical activity and nutrition for university students.
\end{abstract}

Key words: Anthropometric; aerobic capacity; university students; physical activity; nutrition

Physical inactivity and poor cardiorespiratory fitness is strongly associated with an increased risk of premature disease and death (Lakka et al. 2003). Although the relationship between life-threatening health consequences and physical inactivity has been clearly established, the majority of adults continue to lead sedentary lifestyles (Flegal et al. 2002). In the US, approximately one-half of university students' do not meet current physical activity (PA) recommendations (Irwin 2004) and one-third are classified as either overweight or obese (American College Health Association 2005).
World Health Organization (WHO) predicts that the majority of deaths by broad cause $(59 \%)$ are from non-communicable diseases (NCDs).

The current understanding is that PA and physical fitness are reciprocally related and that they exert independent effects on health. Health is also an important factor for academic achievement at school (Novello et al. 1997) and in higher education (Tsouros et al. 1998). The academic achievements of students in higher education institutions face dual

\footnotetext{
${ }^{1}$ Department of Nutrition and Dietetics, Faculty of Medicine and Health Sciences, University Putra Malaysia, Kuala Lumpur, Malaysia

${ }^{2}$ Department of Food Science and Nutrition, Faculty of Applied Sciences, UCSI University, Kuala Lumpur, Malaysia

${ }^{3}$ Department of Community Health, Faculty of Medicine and Health Sciences, University Putra Malaysia, Kuala Lumpur, Malaysia

${ }^{4}$ Exercise and Sports Nutrition Research Group, Faculty of Sports Science and Recreation, University Technology MARA, Shah Alam, Selangor, Malaysia

* Corresponding author (e-mail: mahen@salam.uitm.edu.my)
} 
challenges namely the continuous changes in the demographic pattern of the student and economy (Ansari et al. 2010). Poor school performance is associated with health-compromising behaviors and physical, mental, and emotional problems (Symons \& Cinelli 1997). School performance is also compromised by poor nutrition, substance abuse, sedentarylifestyle, violence and depression (Ansari et al. 2010). Thus, healthy eating and an active lifestyle must be incorporated in daily life for better life and it must start from young. Practicing a good health-related fitness is related to lower risk of disease and improved quality of life. Evidence suggests that maintenance of a healthy weight throughout the lifespan is a key component for protection against non-communicable diseases (NCDs).

The physical fitness among Malaysian university students information is lacking. There was a need to identify and evaluate physical fitness among university students, which will be reference data for future health intervention studies among university students. Therefore, the purpose of the present study was to determine morphological fitness (body fat $\%$ or BF \%; Body Mass Index or BMI; and waist circumference or WC), metabolic fitness (blood glucose, lipid profiles and haemoglobin) and aerobic capacity $\left(\mathrm{VO}_{2} \max \right)$ among a selected public university in Shah Alam Selangor Malaysia.

\section{MATERIALSAND METHODS}

\section{Study Design}

This was a cross-sectional study undertaken among first year students at University Technology MARA (UiTM), Shah Alam during the academic session of the years 2010 to 2012. Ethical approval was obtained from the Ethics Committee of the Faculty of Medicine and Health Science, University Putra Malaysia (UPM). According to the sample size formula; $\mathrm{n}=50+8 \mathrm{~m}$ (Cochran 1977), where " $\mathrm{m}$ " is equal to the number of independent variables, the sample size derived was 324 respondents.

After adding a non-response rate of $20 \%$, a total of 390 students were needed for the study. A list of first year students was obtained from the assistant registrar of the faculty, which showed that there were almost 900 students on the list. A 'systematic random sampling' approach was adopted whereby every alternate student on the list was selected. Later, these students were contacted via email or telephone, and briefed about the study. Those who had current acute illness such as fever and influenza or any chronic disease, had participated in other research projects, or who were more than 25 years old were excluded from the study. In due course after following the inclusion and exclusion criteria, a total of 324 respondents met the inclusion criteria and responded to the data collection. Data protection and confidentiality were observed at all times. A respondent's information sheet was attached to each questionnaire, and respondents were asked to read the information sheet and keep it for future reference. Respondents were also asked to sign a consent form once they agreed to participate in the study. The information on the respondents' personal attributes, such as gender, age, university entry level (matriculation, A-level and O-level), place of accommodation (campus or off-campus), allowance sufficiency with a four-point response scale (Ansari et al. 2010) ( 1 = "always insufficient", 4 = "always sufficient") and scholarship (yes or no) were recorded using the self-administered questionnaire.

The respondents' stature was measured using a non-stretchable stadiometer (SECA 201, Germany). Weight was measured by an Omron HBF-514C full body composition sensing monitor and scale (OMRON, Japan). The waist circumference (WC) was measured 
using a non-stretchable measuring tape, and $\mathrm{BF} \%$ was measured using a bioelectrical impedance analysis (BIA) technique using the Omron HBF-514C (OMRON, Japan). The BMI $\left(\mathrm{kg} / \mathrm{m}^{2}\right)$ was calculated using the individual's height and weight, and classified according to WHO (WHO 2006). The BF\% was classified based on American College of Sports Medicine (American College of Sports Medicine 2009). The WC was based on (International Diabetes Federation International Diabetes Federation 2006). A blood sample was drawn from a subsample of 162 respondents ( 79 males and 83 females) by proportionate stratified sampling, whereby, every other respondent was chosen from the total population list $(n=324)$.

A finger prick sample of blood was drawn by a trained laboratory technician to measure haemoglobin, blood glucose and blood lipids (serum total cholesterol, HDL-cholesterol, LDL-cholesterol, and triglycerides) by the Reflotron ${ }^{\circledR}$ Plus instrument (ROCHE, Switzerland). The cut-off point for hemoglobin was based on WHO (WHO 2001). To measure Maximum Aerobic Capacity $\left(\mathrm{VO}_{2} \max \right)$ levelrespondents had to perform the Queens College Step test (McArdle et al. 1972). Respondents were required to do light warmingup activities prior to actual measurements.

\section{RESULTS AND DISSCUSION}

A total of 324 Malay respondents were recruited, the majority of whom were females $(\mathrm{n}=167 ; 51.4 \%)$. The mean age $( \pm$ S.D. $)$ of the respondents' was $21.77 \pm 1.1$ years old, with almost half of them $(50.1 \%)$ at the age of 22 years. The present study revealed that the respondents had varying background education levels such as diploma (45.5\%), STPM (A-level equivalent) (28.6\%), SPM (O-level) $(23.4 \%)$ and matriculation $(2.5 \%)$. The majority of the respondents lived on campus $(63.0 \%)$, additionally most of the respondents received scholarships (79.3\%) to pursue their studies.

The mean $( \pm \mathrm{SD})$ of BMI of the respondents was $22.5 \pm 4.18\left(\mathrm{~kg} / \mathrm{m}^{2}\right)$. The findings are similar to another local university study (Quah \& Zaitun 2005). Although the majority of the respondents were of average BMI, $14 \%$ of the respondents were underweight and $21 \%$ were overweight and obese (Table 1). However, the mean $( \pm \mathrm{SD})$ BMI of the male students $\left(23.0 \pm 3.9 \mathrm{~kg} / \mathrm{m}^{2}\right)$ was slightly higher than that of female students $\left(22.0 \pm 4.3 \mathrm{~kg} / \mathrm{m}^{2}\right)$. Similar findings were also reported in another study (Saat et al.2010. It is generally believed that young females desire to lose weight while young males basically

Table 1. Distribution of Body Mass Index of the respondents.

\begin{tabular}{l|cc}
\multicolumn{1}{c|}{$\begin{array}{c}\text { BMI }\left(\mathrm{kg} / \mathrm{m}^{2}\right) \\
(\mathrm{n}=324)\end{array}$} & Mean \pm S.D. & $\mathrm{n}(\%)$ \\
\hline Overall & $22.51 \pm 4.18$ & \\
Severe thinness $(<16.00)$ & - \\
Moderate thinness $(16.00-16.99)$ & $9(2.7)$ \\
Mild thinness (17.00-18.49) & $35(10.8)$ \\
Normal (18.50-24.99) & $215(66.3)$ \\
Overweight/pre-obese (25.00-29.99) & $45(13.9)$ \\
Obese 1 (30.00-34.99) & $14(4.3)$ \\
Obese 2 (35.00-39.99) & $5(1.5)$ \\
Obese 3 (>40.00) & $1(0.5)$ \\
\hline
\end{tabular}

Note. Data are expressed as n (\%) unless otherwise indicated.

Based on BMI classification by World Health Organization 2006 
would like to gain weight. The weight gain in males is commonly due to increase in muscle mass. Females are more likely to go on a diet and try other weight-loss practices just to have lower body weight. Nevertheless, the majority $(66.3 \%)$ of the respondents had normal BMI.

The majority of the respondents (93\%) were in the normal $\mathrm{WC}$ range. The mean $( \pm \mathrm{SD})$ of WC was $74.3 \pm 9.01(\mathrm{~cm})$ for males and $68.7 \pm 9.77(\mathrm{~cm})$ for females, which were within the normal range. The Malaysian NCD surveillance (MyNCDs-1) among 2572 Malaysian adults (25-64 years old) using the International Diabetes Federation (IDF) cutoff points, reported a higher prevalence of abdominal obesity at $48.6 \%$ for women and $40.7 \%$ for men (Disease Control Division, Ministry of Health 2006). The difference in the present study might be attributed to the larger proportion of the younger age group from 18 to 25 years old. Nevertheless, the present study revealed that WC was comparable other local university students (Gan et al. 2011). The mean body fat percentages $(\mathrm{BF} \%)$ of the male and female respondents was $16.4 \pm 5.98 \%$ and $26.0 \pm 5.50 \%$, respectively.

The mean $( \pm \mathrm{SD})$ blood glucose $(5.7 \pm$ $0.95 \mathrm{mmol} / \mathrm{l}$ ) was within the normal range, based on Clinical Practice Guidelines Management of Type 2 Diabetes Mellitus 2009, for $94.4 \%$ of the respondents, and there was no significant difference observed within each gender. In addition, in the present study, the glucose reading was similar to fasting blood glucose of Malaysians in 2008 (Lee et al. 2010).

As presented in Table 2, the mean ( \pm SD) of the respondents' serum total cholesterol, HDL-cholesterol, LDL-cholesterol and triglycerides were $4.3 \pm 0.79(\mathrm{mmol} / \mathrm{l}), 0.8 \pm$ $0.18(\mathrm{mmol} / \mathrm{l}), 3.0 \pm 0.59(\mathrm{mmol} / \mathrm{l})$ and 1.1 $\pm 0.62(\mathrm{mmol} / \mathrm{l})$, respectively. The current findings reveal that total cholesterol levels were lower when compared with data on Malaysian lipid profiles in 2008 (Lee et al. 2010), which may be due to the younger age group (18-25 years old) in the present study. While, in haemoglobin measurement (Table 3), mild or moderate anaemia was reported in the current study (34.5\%), which is slightly higher when compared to another study conducted in Tuaran District of Sabah (Leng et al. 2004).

Table 2. Lipid profile of the respondents $(n=162)$.

\begin{tabular}{l|c}
\hline \multicolumn{1}{c|}{ Lipid $(\mathrm{mmol} / \mathrm{l})$} & Mean \pm S.D \\
\hline Serum total cholesterol & $4.29 \pm 0.79$ \\
HDL-cholesterol & $0.75 \pm 0.18$ \\
LDL-cholesterol & $2.98 \pm 0.59$ \\
Triglycerides & $1.10 \pm 0.62$ \\
\hline
\end{tabular}

Note: Data are expressed as n (\%) unless otherwise indicated.

Based on cut-offs by International Diabetics Federation 2006

The majority of the respondents had poor aerobic capacity $(70.7 \%$ males and $25.7 \%$ females) (Table 4). It is also noted that the male respondents generally had a higher $\mathrm{VO}_{2}$ max than their female counterparts. The $\mathrm{VO}_{2}$ max values of the present study $(51.17 \pm 3.93 \mathrm{ml} / \mathrm{kg} / \mathrm{min})$ were lower when compared with another study $(56.8 \pm 3.5 \mathrm{ml} / \mathrm{kg} / \mathrm{min})$ (Singh et al. 1989).

Although our study relied on the inclusion of a large, convenient sample, a major limitation still exists, data were self-reported and crosssectional (does not infer causal relationships). The limited blood samples are obtained that may not be able to give comprehensive metabolic profiles. The aerobic capacity measurement may need to include lab protocol using treadmill to obtain actual aerobic capacity. Food consumption should have been obtained which will able to portray the eating habits as well as energy consumption. Due to the lack of direct physical activity and food consumption assessment in our current study, concrete evidence to support this finding requires further investigation. 
Table 3. Distribution of haemoglobin of the respondents by gender.

\begin{tabular}{l|cc}
\hline \multicolumn{1}{c|}{$\begin{array}{c}\text { Haemoglobin }(\mathrm{g} / \mathrm{l}) \\
(\mathrm{n}=162)\end{array}$} & Mean \pm S.D & $\mathrm{n}(\%)$ \\
\hline Male $(\mathrm{n}=79)$ & $147.4 \pm 14.9$ & - \\
Severe anemia $(<80)$ & & - \\
Moderate anemia $(80-109)$ & & $19(24.0)$ \\
Mild anemia $(110-129)$ & & $60(76.0)$ \\
Non-anemia $(\geq 130)$ & & - \\
Female $(\mathrm{n}=83)$ & $122.9 \pm 13.7$ & $3(4.5)$ \\
Severe anemia $(<80)$ & & $34(40.1)$ \\
Moderate anemia $(80-109)$ & & $46(55.4)$ \\
Mild anemia $(110-119)$ & & \\
Non-anemia $(\geq 120)$ & & \\
\hline
\end{tabular}

Note. Data are expressed as n (\%) unless otherwise indicated. Based on cut-offs by WHO, UNICEF, UNU2001

Table 4. Distribution of $\mathrm{VO}_{2}$ max of the respondents by gender.

\begin{tabular}{l|cc}
\hline $\begin{array}{c}\mathrm{VO}_{2} \max (\mathrm{ml} / \mathrm{kg} / \mathrm{min}) \\
(\mathrm{n}=324)\end{array}$ & Mean $\pm \mathrm{S} . \mathrm{D}$ & $\mathrm{n}(\%)$ \\
\hline Male $(\mathrm{n}=157)$ & $51.17 \pm 3.93$ & \\
Excellent $(\geq 48.20)$ & & $16(10.2)$ \\
Good $(44.23-48.19)$ & & $16(10.2)$ \\
Fair $(40.98-44.22)$ & & $14(8.9)$ \\
Poor $(<40.98)$ & & $111(70.7)$ \\
Female (n=167) & $38.82 \pm 3.93$ & \\
Excellent $(\geq 40.98)$ & & $13(7.8)$ \\
Good $(36.65-40.97)$ & & $29(17.4)$ \\
Fair $(33.76-36.64)$ & & $82(49.1)$ \\
Poor $(<33.76)$ & & $43(25.7)$ \\
\hline
\end{tabular}

Note. Data are expressed as n (\%) unless otherwise indicated.

Based on cut-offs American College of Sports Medicine 2006

The metabolic risk factors for cardiovascular disease and Type 2 diabetes are increasingly apparent in young adults (Ramachandran et al. 2012). There is no data available on physical fitness among younger age group in Malaysia. Physical fitness and physical activity are strong determinants for health outcomes. In fit individuals, confer a lower metabolic risk profile. It is noted from recent National Health Morbidity Survey (NHMS), Malaysian are generally inactive and non-communicable disease increasingly apparent in adults
(National Health and Morbidity Survey 2011). The respondents' blood profiles were good; $\mathrm{BF} \%$ and $\mathrm{WC}$ are within normal range. Conversely, the poor aerobic capacity, which means they are not physically fit, may predispose to non-communicable disease in future.

\section{CONCLUSION}

The current study provides important insight into the level of physically active lifestyles and metabolic profile in the university-aged 
population, revealed that the respondents in this study have low physical fitness level, and there is evidence of under- as well as overnutrition (overweight and obese) issues among undergraduates. Despite knowing the health benefits associated with an active lifestyle, the majority of young adults do not engage in sufficient levels of physical activity. Increasing physical activity and obesity prevention has been identified as the top priorities in the national health agenda, which may require additional focus among university students. PA needs to be increased and emphasized during university life because it is likely that the undergraduates may persist in this low level of PA, or even decrease it further in the years following graduation. Establishing healthy lifestyle from the time they are in university would ensure that they are in better health when they enter the workforce where stress levels and time demands will be even greater. Additionally, it is also important that varsity-aged students are educated concerning how important is the simple height and weight measurement to calculate the BMI and understand that this measure is abasic healthscreening tool. On the other hand, the university should also incorporate a health promotion programme propounding PA and nutrition into the university's general education requirements.

\section{ACKNOWLEDGMENTS}

The authors would like to thank University Putra Malaysia for the technical and financial support under the Research University Grant Scheme. The authors wish to acknowledge the Faculty of Sports Sciences and Recreation (FSR), University Technology MARA (Shah Alam) and the FSR Physiology Laboratory. The authors express their utmost gratitude to the respondents for their participation.

Date of submission: December 2013

Date of acceptance: April 2014

\section{REFERENCES}

American College Health Association 2005, 'The American College Health Association National College Health Assessment (ACHA-NCHA)', Spring 2003 reference group report, Journal of American College Health, vol. 53, pp. 199-210.

American College of Sports Medicine 2009, ACSM's guidelines to exercise testing and prescription, 8th edn, Baltimore: Williams \& Wilkins.

Ansari,W \& Stock, C 2010, 'Is the health and wellbeing of university students associated with their academic performance? Cross sectional findings from the United Kingdom', International Journal of Environmental Research and Public Health, vol. 7, pp. 509-527.

Cochran,WG 1977, Sampling techniques, 3rd edn, New York, John Wiley.

Flegal, K, Carroll, J,Ogden, C \& Johnson, C 2003, 'Prevalence and trends in obesity among US adults 1999-2000', Journal of the American Medical Association, vol. 286, pp. 1195-1200.

Gan, WY, Mohd, NMT, Zalilah, MS \& Hazizi, AS 2011, 'Differences in eating behaviours, dietary intake and body weight status between male and female Malaysian university students', Mal. J. Nutrition, vol. 17, no. 2 pp. 213-228.

Institute for Public Health, Kuala Lumpur, Ministry of Health, Malaysia 2011, National Health and Morbidity Survey.

International Diabetes Federation 2006, 'The IDF consensus worldwide definition of the metabolic syndrome', viewed 3 June 2013, <http://www.idf. org/webdata/docs/IDF_Metasybdrome_definition. pdf $>$.

Irwin, J 2004, 'Prevalence of university students' sufficient physical activity', a systematic review, Perceptual and Motor Skills, vol. 98, pp. 927-943.

Lakka, TA, Laaksonen, DE, Lakka, HM, Ma Nnikk N, Niskanen, LK, Rauramaa, R \& Salonen, JT 2003, 'Sedentary lifestyle, poor cardiorespiratory fitness, and the metabolic syndrome', Med. Sci. Sports Exerc., vol. 35, no. 8, pp. 1279-1286.

Lee, PY, Ong, TA, Muna, S, Alwi, SSAR \& Kamarudin, K 2010, 'Do university students have high cardiovascular risk? A pilot study from 
Universiti Malaysia Sarawak (Unimas)', Mal. Family Physician, vol. 5, no. 1.

Leng, HF, Geok, LK, E-Siong, T \& Dhanaraj, P 2004, 'Iron status and dietary iron intake of adolescents from a rural community in Sabah, Malaysia', Asia Pacific J. Clin. Nutr., vol. 13 no. 1, pp. 48-55.

McArdle, WD, Katch, FI \& Pechar, PS 1972, 'Reliability and interrelationships between maximal oxygen uptake, physical work capacity and step test scores in college women', Medicine and Science in Sports, vol. 4, pp. 182-186.

Ministry of Health, Malaysia 2009, Clinical practice guidelines - management of type 2 diabetes mellitus 2009, 4th edn, Ministry of Health, Malaysia, viewed 3 June 2013, <http://www.moh. gov.my/cpgs>.

Ministry of Health 2006, Disease Control Division, MyNCDS-1 Malaysia NCD Surveillance-1 2005/2006, NCD Risk Factors in Malaysia, NonCommunicable Disease Section, Putrajaya.

Novello, AC, Degraw, C \& Kleinman, D 1997, 'Healthy children ready to learn: an essential collaboration between health and education', Public Health Rep., vol. 107, pp. 3-15.

Quah, MM \& Zaitun, Y 2005, 'Relationship between the level of physical activity and indicator of obesity among a sample of university students', in 20th Scientific Conference of the Nutrition Society of Malaysia, pp. 24-25.
Ramachandran, A, Snehalatha, C, Shetty, AS \& Nanditha, A 2012, 'Trends in prevalence of diabetes in Asian countries', World J. Diabetes, vol. 15 , no. 3(6), pp. 110-17.

Saat, NZM, Ishak, I, Lubis, SH, Wen, SH, Suriyanee Mohd, SNL, Zakaria, NS \& Ee, TX 2010, 'Stress and its relationship with body mass index among biomedical science students in Kuala Lumpur, Malaysia', ASEAN Journal of Psychiatry, vol. 11, no. 2, pp. 190-197.

Singh, R, Singh, HJ \& Sirisinghe, RG 1989, 'Cardiopulmonary fitness in a sample of Malaysian population', Jpn. J. Physiolvol., vol. 39 , no. 4, pp. 475-85.

Symons, CW \& Cinelli, B 1997, 'Bridging student health risks and academic achievement through comprehensive school health programs', J. School Health, vol. 67, pp. 220-228.

Tsouros, AD, Dowding, G, Thompson, J, \& Dooris, M 1998, Health promoting universities-concept, experience and framework for action, World Health Organization, Copenhagen, Denmark.

World Health Organization 2001, WHO, UNICEF, UNU, Iron deficiency anaemia: assessment, prevention and control, a guide for programme managers, Geneva.

World Health Organization Global database on Body Mass Index 2006, viewed 2 February 2012, <http:// apps.who.int/bmi/index.jsp?introPage=intro_3. html>. 